\title{
Hot-water-soluble Carbon and Surface Properties of Water Repellent Soils
}

\author{
Irena D. Atanassova ${ }^{1}$, Stefan H. Doerr ${ }^{2, *}$ \\ ${ }^{1}$ Nikola Poushkarov Institute of Soil Science, Agrotechnolgies \& Plant Protection, Bulgaria \\ ${ }^{2}$ College of Science, Department of Geography, Swansea University, UK
}

Copyright $(\mathcal{C} 2015$ by authors, all rights reserved. Authors agree that this article remains permanently open access under the terms of the Creative Commons Attribution License 4.0 International License

\begin{abstract}
Hot-water-extraction of water repellent soils from Australia, Portugal and UK eliminated soil water repellency (SWR) in the soils studied. Gas chromatography/mass spectrometry (GC/MS) analysis showed that the dominant compounds were aromatic acids, short chain dicarboxylic acids $\left(\mathrm{C}_{4}-\mathrm{C}_{9}\right)$, sugars and esters of stearic and palmitic acids. Aromatics and dicarboxylic acid contents increased upon saponification due to cleavage of ester bonds of high molecular weight and polar compounds. Specific surface area and pore distribution showed that the sandy loam and loamy sand soils from Australia had micropores and adsorbed water more efficiently than the sands, while the sandy loam soil from Portugal having a higher content of aromatics in the hot-water-soluble extracts, was strongly water repellent. SWR may intensify upon drought. It has an effect upon soil organic matter (SOM) decomposition and plant productivity, as well as the microbial community structure and the overall carbon balance.
\end{abstract}

Keywords Soil Water Repellency, Hot-water-soluble-carbon, Aromatics, Esters

\section{Introduction}

Soil water repellency (SWR) is a phenomenon which prevents water from penetrating into the soil and is recorded in soils of different types, texture, climates and land uses [6]. It is considered to be a soil organic matter (SOM) stabilization mechanism, enhancing carbon sequestration and reducing $\mathrm{CO}_{2}$ emissions. These benefits are due to the presence of specific organic compounds coating soil particles and presenting a hydrophobic surface towards the soil pores, thus preventing rapid microbial decomposition of SOM [11]. However, in longer term soil water repellency leads to reduced plant especially if especially if climate change leads to an increased soil drought and water scarcity.

Hot water soluble carbon (HWSC) has been suggested as a sensitive indicator of the effects of climate change and soil management practices on carbon sequestration potential and soil sustainability. It is positively correlated with soil aggregation, soil microbial biomass, microbial nitrogen, total carbohydrates and total C [10]. Water soluble organic matter (WSOM) was found to be dominated by sugars, aromatics and $\mathrm{N}$-containing compounds indicating origin from soil microbial biomass, root exudates and lysates $[12,14,15]$. It has been shown that not only lipophilic and amphiphilic [9], but also polar compounds such as phenolics, short-chain diacids, and saccharides play an important role in SWR development and the stabilization of hydrophobic interactions [2]. To our knowledge few studies to date [1,3] have been concerned with the molecular composition of solvent soluble fractions of hot water soluble extracts of water repellent soils obtained under conditions of accelerated solvent extraction (ASE) and using gas chromatographymass spectrometry (GC/MS).

In this study we give emphasis to: (i) the effects of HWSC on soil hydrophobicity; (ii) the molecular composition of HWSC and (iii) the link between surface characteristics and molecular structure of HWSC in water repellent soils of different texture.

\section{Materials and Methods}

Soils with different levels of soil water repellency under Eucalyptus vegetation in South-East Australia (GP, NT, ML, AUS), North-central Portugal (PO), and under dune herbs and grass vegetation in the SW-United Kingdom (UK) were sampled from 0-5 cm depth (Table 1). Bulk soil samples in South-East Australia were pooled from at least five areas more than 2 meters apart [8]. In the case of the Portuguese soil (PO) and the UK soils, samples from a depth $(0-10 \mathrm{~cm})$ from similar parent material and land use were collected [9]. Particle size analysis was performed on Beckman Coulter Particle size analyzer. The Australian soils GP, NT and UK are classified as sands of medium sand texture (mean particle diameter $268 \mu \mathrm{m} ; 295 \mu \mathrm{m}$ and $339 \mu \mathrm{m}$, respectively). The AUS soil is classified as loamy sand, while the PO and ML soils are sandy loams. The content of clay was $<1 \%$ for all the soils studied. Silt contents were $0 \% ; 7 \% ; 7,5 \%$ in the 
case of UK, GP and NT soils, and 30\%, $12 \%$ and $54 \%$ for the ML, AuS and PO soils. The soil texture classification is given in Table 1.

Sample preparation involved air-drying and passing through a $2-\mathrm{mm}$ sieve before further analysis. Total organic carbon of sieved $(<250 \mu \mathrm{m})$ soil material was measured with a Skalar Primacs SC TOC Analyzer (combustion T $1050^{\circ} \mathrm{C}$ ), specific surface area (SSA) was determined by $\mathrm{N}_{2}$ adsorption performed on $\mathrm{mm}$ fraction with a Micromeritics ASAP 2020 surface area analyzer at $-196^{\circ} \mathrm{C}$. Samples were degassed at $110^{\circ} \mathrm{C}$ for $12 \mathrm{~h}$ prior to analysis. Specific surface areas were calculated using the BET equation in the $0.05-0.3$ range of relative pressure. The equation used was:

$$
\mathrm{V} / \mathrm{V} \infty=\mathrm{C} \cdot \mathrm{Z} /((1-\mathrm{Z}) \cdot\{1-(1-\mathrm{c}) \cdot \mathrm{Z}\})
$$

where

$$
\begin{aligned}
& \mathrm{Z}=\mathrm{p} / \mathrm{p}_{0} ; \mathrm{p} / \mathrm{p}_{0}=\text { relative pressure } \\
& \mathrm{c}=\text { constant; }
\end{aligned}
$$

$V_{\infty}=$ monolayer capacity (volume corresponding to monolayer coverage).

Soil water repellency was measured before and after extraction with hot water using the water drop penetration time (WDPT) method after equilibration at an atmosphere of $20^{\circ} \mathrm{C}$ and $45-55 \%$ relative humidity for $24 \mathrm{~h}$ [7]. Free $\mathrm{Fe}$ and $\mathrm{Al}$ oxides and hydroxides and organically complexed forms were determined by the dithionite-citrate method and the pyrophosphate method and subsequently analyzed by atomic absorption spectroscopy (Varian Spectra 22FS).

Soil samples were subjected to accelerated solvent extraction (ASE) with water $\left(10.3 \times 10^{6} \mathrm{~Pa}, 100^{\circ} \mathrm{C}\right.$, lyophilized at $\left(-50^{\circ} \mathrm{C}\right)$ and fractionized in dichloromethane (DCM), DCM/iso-propanol and methanol (MeOH). Each extract was split into half and one of the aliquots was saponified (reflux for $6 \mathrm{~h}$ under $\mathrm{N}_{2}$ with $0.5 \mathrm{M} \mathrm{NaOH}$, methanol $(\mathrm{MeOH}) / \mathrm{H}_{2} \mathrm{O} 9 / 1 \mathrm{v} / \mathrm{v}$ and stirring overnight at room temperature). The saponified lipids were extracted with $\mathrm{DCM}$ after acidification with $\mathrm{HCl}(\mathrm{pH}$ 1.5), before being silylated and analyzed by GC/MS. An Agilent 6890 gas chromatograph, splitless mode and equipped with a 5975 B mass-selective detector, was used. Separation was done using HP- $5 \mathrm{~ms}$ capillary columns $(30 \mathrm{~m} \times 0.25 \mathrm{~mm}$ I.D., film thickness $0.25 \mu \mathrm{m}$ ) and $\mathrm{He}$ as a carrier gas. The gas chromatograph was programmed in the following temperature mode: initial temperature $60^{\circ} \mathrm{C}$, hold $1 \mathrm{~min}$, linear ramp $10^{\circ} \mathrm{C} / \mathrm{min}$ to $180^{\circ} \mathrm{C}$, then ramped at $4^{\circ} \mathrm{C} / \mathrm{min}$ to $300^{\circ} \mathrm{C}$ and held for $15 \mathrm{~min}$. The MS detection was full scan, $(\mathrm{m} / \mathrm{z}) 50-650$ with a cycle time 2.28 scans/s and EI ionization of $70 \mathrm{eV}$. Identification was based on comparing the mass spectra of the chromatographic peaks to those in the NIST-MS library, comparisons with authentic standards, GC retention times, literature mass spectra and interpretation of mass spectrometric fragmentation patterns [2].

For the chemical and physical soil analysis, as well as for the gas chromatography/mass spectrometry analysis triplicate soil samples were used. Compounds differences between soils were analyzed by the t-test at $\mathrm{p}=0.05$ (SPSS 19 for Windows).

\section{Results and Discussion}

The sandy loam soils Po and ML, and the loamy sand AuS contain more free and organically complexed iron $\left(\mathrm{Fe}_{\mathrm{cd}}\right.$ and $\left.\mathrm{Fe}_{\mathrm{pyr}}\right)$ than the sandy NT, GP and UK soil. These data correspond to the larger specific surface area (SSA) and the higher content of total organic carbon (TOC) determined for the ML, AuS and PO soils (Table 1 and Table 2). Contrary to the ML sandy loam soil from Australia, the PO soil from Portugal with similar texture and free sesquioxide contents, was strongly water repellent.

\begin{tabular}{|c|c|c|c|c|c|c|c|c|}
\hline $\begin{array}{c}\text { Soil } \\
\text { code \& } \\
\text { texture } \\
\text { (USDA) }\end{array}$ & $\begin{array}{c}\text { TOC } \\
\text { before HWE } \\
\text { wt } \%\end{array}$ & $\begin{array}{c}\text { TOC } \\
\text { after } \\
\text { HWE wt \% }\end{array}$ & $\begin{array}{c}\text { WDPT } \\
\text { before } \\
\text { HWE } \\
(\mathrm{s})\end{array}$ & $\begin{array}{c}\text { WDPT } \\
\text { after HWE } \\
\text { (s) }\end{array}$ & $\begin{array}{c}\mathrm{Fe}_{\mathrm{cd}} \\
\%\end{array}$ & $\begin{array}{c}\mathrm{Al}_{\mathrm{cd}} \\
\%\end{array}$ & $\mathrm{Fe}_{\mathrm{pyr}} \%$ & $\mathrm{Al}_{\mathrm{pyr}} \%$ \\
\hline $\mathrm{GP}^{\mathrm{a}}$ sand & 3.9 & 3.5 & 993 & $<5$ & 0.07 & 0.03 & 0.03 & 0.08 \\
\hline $\mathrm{NT}^{\mathrm{a}}$ sand & 3.4 & 3.1 & 287 & $<5$ & 0.16 & 0.03 & 0.03 & 0.04 \\
\hline $\mathrm{ML}^{\mathrm{a}}$ sandy loam & 9.0 & 7.9 & 10 & $<5$ & 0.58 & 0.23 & 0.25 & 0.69 \\
\hline AuS ${ }^{\mathrm{c}}$ loamy sand & 9.3 & 7.8 & $<5$ & $<5$ & 0.27 & 0.14 & 0.2 & 0.4 \\
\hline $\mathrm{UK}^{\mathrm{b}, \mathrm{c}}$ sand & $1.3^{\mathrm{b}}$ & $1.2^{\mathrm{b}}$ & $205^{\mathrm{b}}$ & $<5^{\mathrm{b}}$ & $0.2^{\mathrm{c}}$ & $0.005^{\mathrm{c}}$ & $0.0007^{\mathrm{c}}$ & $0.007^{\circ}$ \\
\hline $\mathrm{PO}^{\mathrm{c}}$ sandy loam & 9.5 & 8.1 & 757 & $<5$ & 0.76 & 0.37 & 0.6 & 0.56 \\
\hline
\end{tabular}

Table 1. Total organic carbon (TOC) and WDPT of the soil samples before and after hot water extraction (HW). ${ }^{a}$ data from Atanassova \& Doerr (2010); ${ }^{\mathrm{b}}$ Atanassova et al., (2014); ${ }^{\mathrm{C}} \mathrm{AuS}, \mathrm{PO}$, and UK this study. 
The extracts from the sandy loams from Australia and Portugal were dark brown colored due to water soluble humic substances of polyphenolic nature. Aromatics and their derivatives were detected with high intensity, the most abundant being benzaldehyde, benzoic, hydroxy-, dihydroxybenzoic and methoxyhydroxybenzoic acids (example of $\mathrm{PO}$ soil, $\mathrm{MeOH}$ extract), (Figure 1a, b) and Figure 3 (two sands and two sandy loam soils are presented). Hydroxybenzoic acids are components of hydrolysable tannins. In the non-saponified extracts predominantly sugars in the GP, NT and ML soils, and aromatics (PO soil from Portugal) were detected in the $\mathrm{MeOH}$ fraction. Hot water extraction detaches polar components from particles surfaces, as well as micelle like colloidal material.

Short chain $\mathrm{C}_{7}, \mathrm{C}_{8}$ and $\mathrm{C}_{9}$ dicarboxylic acids dominated the total ion current (TIC) trace in the sandy loam soils. These acids are suspected to originate from microbial metabolism [13]. Adsorption of the short chain $\omega$-hydroxy and dicarboxylic fatty acids takes place through coordination to the polymeric organic matrix or ligand exchange on sesquioxides. The sandy loam soils of heavier texture, i.e. the ML, PO and AuS contribute to a larger extent to the sorption of these acids, than the GP, NT and UK sands. Sugars were detected at high abundance in the more polar dichloromethane/iso-propanol fraction in the soils studied ( $>65 \%$ of TIC traces). Of highest intensity were hexoses (mannose), (Figure 2) and disaccharides (turanose). The neutral sugars represent the labile pool of soil organic carbon and provide energy for soil microorganisms. Pentoses, e.g. xylose and arabinose are important constituents of plants, while hexoses, e.g. mannose, ramnose and galactose are considered to be products of microbial synthesis [4].

Upon saponification the amount of aromatics and polar dicarboxylic acids increased in the methanolic extracts (Figures 2,4). Organic carbon saturation with aromatics and dicarboxylic acids was higher in the sandy loam ML soil than in the sandy GP and NT soils. Upon alkaline hydrolysis aromatics can be liberated from carbohydrate moieties covalently bound to phenolic structures in lignocellulose-degradation products through cleavage of ester and glycosidic bonds thus differentiating between "free" and "bound" aromatics and diacids. The occurrence of salicylic, vanillic, protocatechuic and syringic acids therefore probably reflects the contribution of lignin-derived components of HWSC ester-linked between the core lignin and polysaccharides.

Surface properties and pore distribution are presented in Table 2. It's obvious that the sandy loams and the loamy sand possess micro- and mesopores, contrary to the sandy UK, NT and GP soils. The soils with higher specific surface area (SSA) possess higher contents of TOC and HWSC. We speculate that the presence of the hydrophobic compounds (e.g. oleic, palmitic and stearic acid esters) in the water extracts is due to solubilization from micelle-like colloidal particles in HWSC. Both "free" and esterified aromatics contribute to water repellency elimination.
Water repellency generally appears in dry soils and disappears when the soil reaches a certain critical moisture threshold $[5,6]$. It has been shown by Doerr et al [6] that a complex relationship exists between water repellency and soil water content, while Dekker et al [5] define a transition zone, rather than a sharp threshold. The variability of the critical water content (CWC) is caused by the heterogeneous distribution of water in and around the micro- and mesopores of the aggregates of soil, and is controlled by the concentration and distribution of hydrophobic compounds at surfaces of all soil aggregate-size fractions $[5,16]$.

In the case of PO soil, the higher water repellency, despite the finer texture and the higher micropore and specific surface areas might be due to: (i) the higher TOC and type of water repellency causing compounds incorporated into larger molecules of humic substances, and forming water impermeable aggregates. In this soil $>$ than $60 \%$ of HWSC was unextractable by organic solvent due to the presence of tannins, similarly to ML and AuS soils; (ii) the Portuguese soil contained more aromatics originating from the polyphenolic framework of tannins; (iii) the higher critical water content at which the repellency causing compounds coat the surface particles in organic soils and soils of finer texture.

Except on texture, the differences in the degree of water repellency between the soils studied depend on multiple factors including specific surface area, free sesquioxide content and the content and composition of amphiphilic, lipophilic and polar compounds. We can speculate that the Eucalyptus vegetation and the content and quality of soil organic matter (SOM) in combination with the factors mentioned above, dictate the development and persistence of surface water repellency in the studied soils.

The hot-water-soluble carbon composition, as part of TOC results from microbially mediated soil reactions and is potentially the most susceptible to oxidation to $\mathrm{CO}_{2}$. Thus, HWSC has a greatest impact on global climate change. The signature of amphiphilic, hydrophobic and polar organic compounds identified in the extracts and the expected changes in their molecular composition due to climate change, makes them valuable indicators in water repellent soils and ecosystem functioning, in general.

\section{Conclusions}

Based on the composition of organic solvent extracts of HWSC, we can speculate that compounds responsible for soil water repellency are present in this fraction, because of the complete elimination of SWR following extraction with hot water. Specific reasons for elimination are due to: (i) extraction of critical quantity of HWSC and removal of amphiphilic aromatics and polar sugars; (ii) removal of hydrophobic compounds $\left(\mathrm{C}_{16}\right.$ and $\mathrm{C}_{18}$ fatty acid esters) and high molecular weight humic material (tannins) in the case of the sandy loam and loamy sand soils; (iii) enhancement of desorbed colloidal organic carbon of complex nature 
including ester bound aromatics and diacids; (iv) the higher TOC and the specific surface area of the soils of autohydrolysis of ligno-cellulosic structures of particulate and humified organic matter under the conditions of accelerated solvent extraction; (v) desorption of polar compounds is critical for water repellency elimination; (vi)

finer texture, contribute to more efficient desorption of polar and amphiphilic compounds, including aromatics and sugars.

Table 2. Surface properties of the experimental soils.

\begin{tabular}{|c|c|c|c|c|}
\hline Soil Code & $\begin{array}{c}\text { BET surface area } \\
\mathrm{m}^{2} / \mathrm{g}\end{array}$ & $\begin{array}{c}\text { Micro-pore volume } \\
\mathrm{cm}^{3} / \mathrm{g}\end{array}$ & $\begin{array}{c}\text { Micro-pore area } \\
\mathrm{m}^{2} / \mathrm{g}\end{array}$ & $\begin{array}{c}\text { External area } \\
\mathrm{m}^{2} / \mathrm{g}\end{array}$ \\
\hline PO & 4.18 & 0.000252 & 0.6018 & 3.577 \\
\hline NT & 0.43 & - & - & - \\
\hline GP & 0.32 & - & - & - \\
\hline ML & 4.41 & 0.000166 & 0.3488 & 4.065 \\
\hline AuS & 2.44 & 0.000215 & 0.4179 & 2.023 \\
\hline UK & 0.42 & - & - & - \\
\hline
\end{tabular}

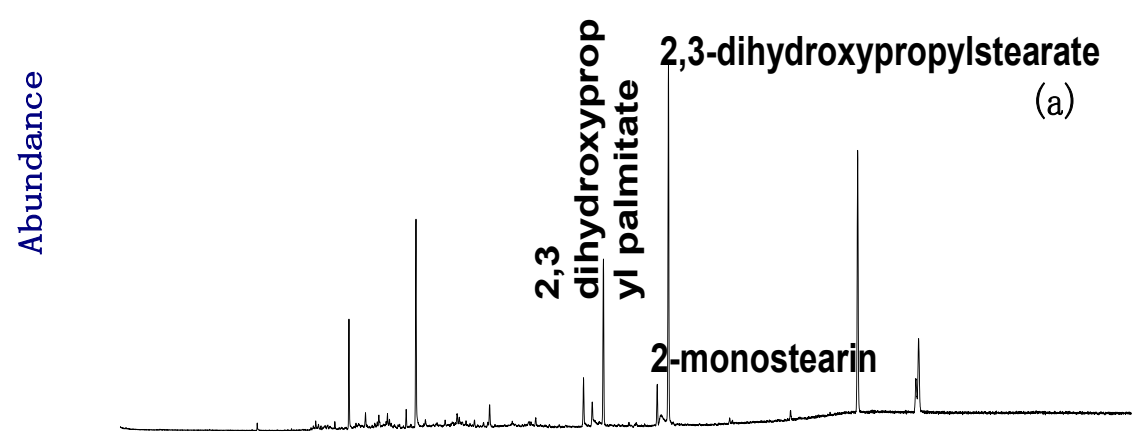

Time-->

8

Time-->

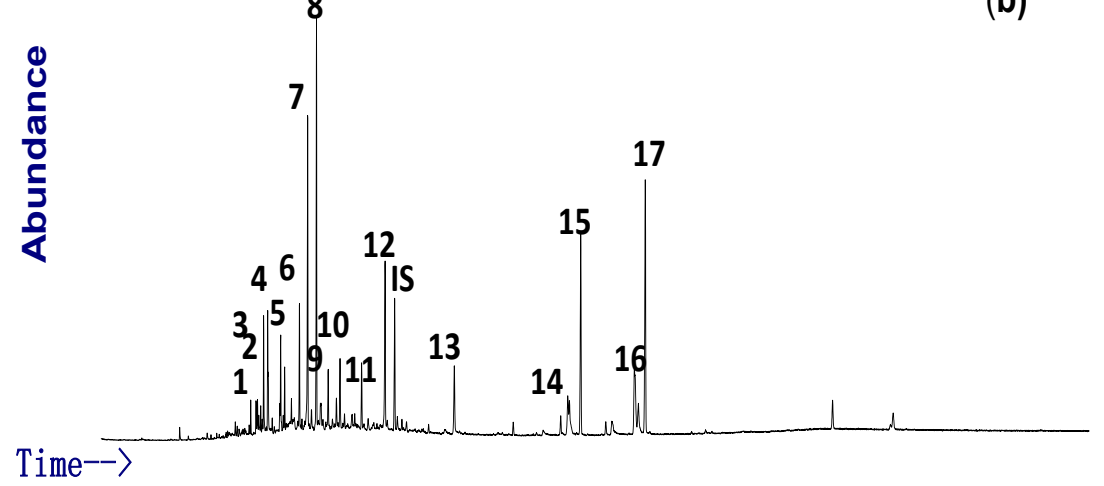

Figure 1. TIC chromatogram of the DCM/iso-propanol and $\mathrm{MeOH}$ fractions of the HWSC extracts of the soil from Portugal (PO). 1. 4-hydroxyphenylethanol; 2. $\mathrm{C}_{7}$ dioic acid, 3. 4-hydroxybenzoic acid; 4. Sugar acid; 5. $\mathrm{C}_{8}$ dioic acid; 6. 3-methoxy-4-hydroxybenzoic acid; 7. azelaic acid $\left(\mathrm{C}_{9}\right.$ dioic); 8. 3,4-dihydroxybenzoic acid; 9. $\mathrm{C}_{14}$ acid; 10. 3,5-dimethoxy-4-hydroxybenzoate; 11. 3,4,5-trihydroxybenzoic acid; 12. $\mathrm{C}_{16}$ acid; IS= 10-nonadecanone; 13. $\mathrm{C}_{18}$ acid; 14. 2-monopalmitin; 15. 2,3-dihydroxypropyl palmitate; 16. 2-monostearin; 17. 2,3-dihydroxypropylstearate. 


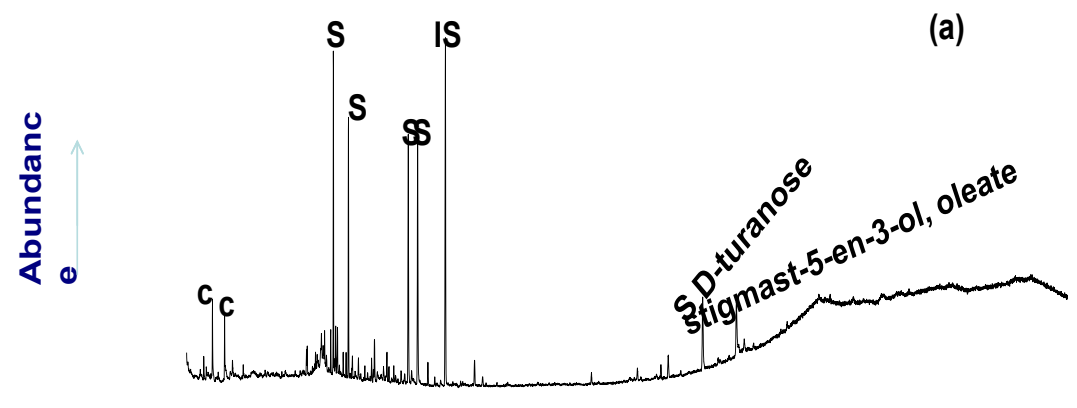

Time-->

IS

(b)

8
0
$\frac{0}{0}$
$\frac{0}{5}$
$\frac{0}{4}$

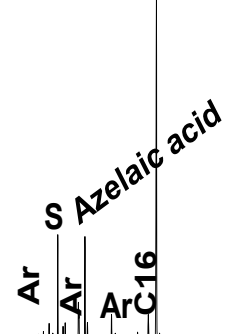

\section{Time-->}

Figure 2. TIC chromatogram of the $\mathrm{MeOH}$ extract of a sandy water repellent soil (GP) (a) non-saponified and (b) saponified extract. $\mathrm{S}=$ sugar; $\mathrm{Ar}=$ aromatic compound; $\mathrm{c}=$ contaminant; Aze $=$ azelaic acid; $\mathrm{C}_{16}$ palmitic acid.

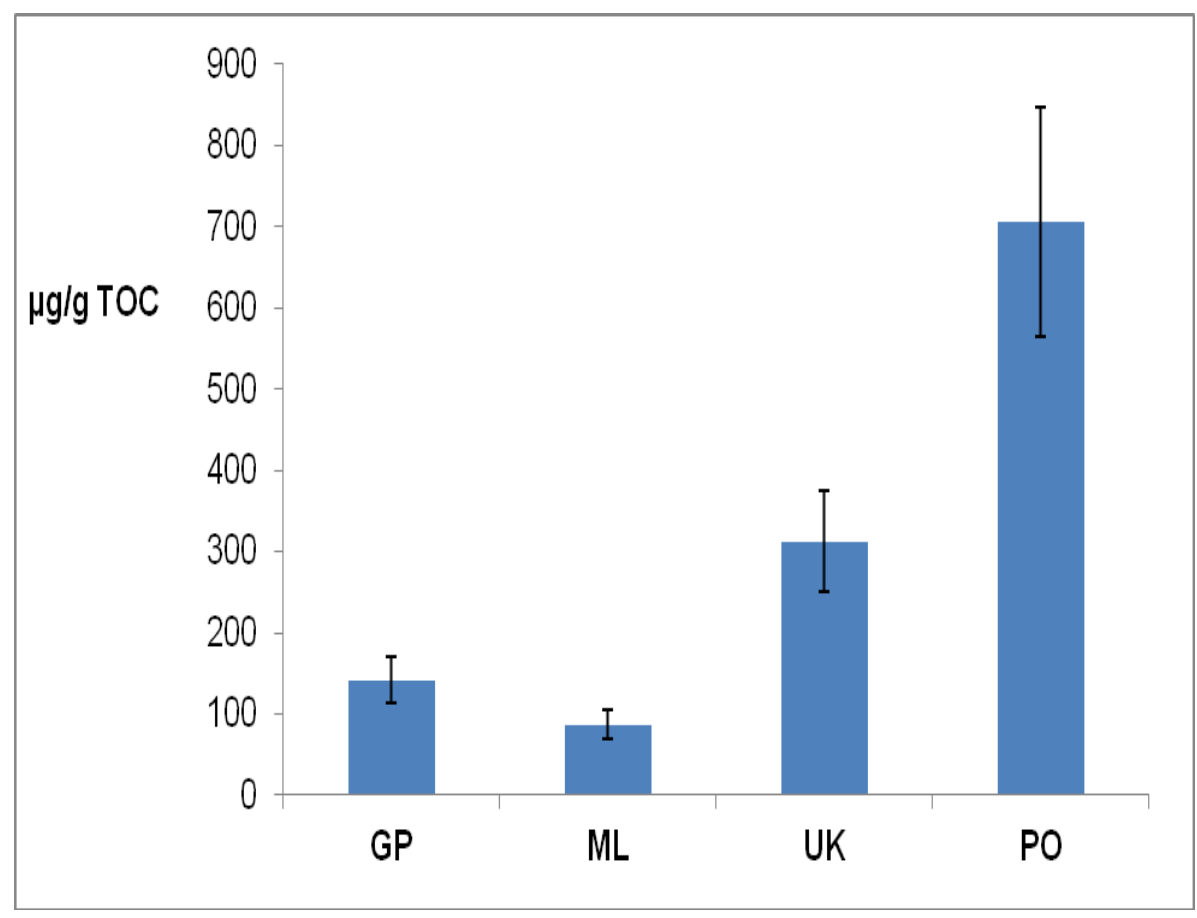

Figure 3. Contents of aromatics in hot water soluble extracts (HWSE) from four WR soils in the DCM, DCM/IPA and MeOH fractions based on the GC-MS data (only identified compounds of relative abundance $>0.1 \%$ of total peak area were computed and included). 


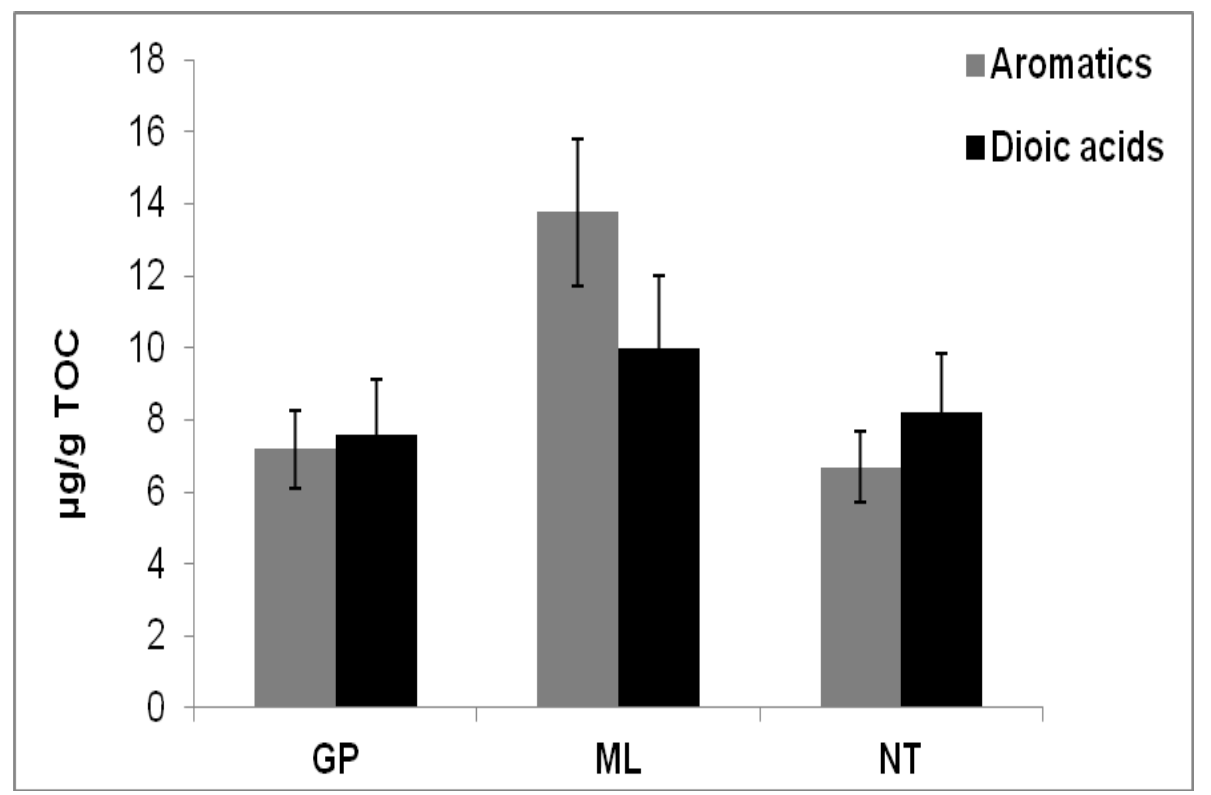

Figure 4. Aromatics and dicarboxylic $\left(\mathrm{C}_{7}-\mathrm{C}_{9}\right)$ acids in the saponified $\mathrm{MeOH}$ fractions of HWSE from the sandy GP, NT and ML sandy loam soils.

\section{Conflict of Interests}

The authors declare that there are no conflicts of interests.

\section{Acknowledgements}

This study was supported by NERC Advanced Fellowship NER/J/S/2002/00662 and EC project "Water Reuse" N 516731.

\section{REFERENCES}

[1] Atanassova I.D., Doerr S.H., 2014. Experimental approaches for analysis of organic compounds in water soluble fractions from hydrophobic soils. Silva Balcanica. 15 (2), 43-49.

[2] Atanassova I., Doerr S., 2010. Organic compounds of different extractability in total solvent extracts from soils of contrasting water repellency. European Journal of Soil Science 61, 298-313.

[3] Atanassova I.D., Doerr S.H., Mills G.L., 2014. Hot-Water-Soluble Organic Compounds Related to Hydrophobicity in Sandy Soils. In Hartemink A.E., McSweeney K. (Eds.). Progress in Soil Science: Soil Carbon. Springer International Publishing, Switzerland, 137-146.

[4] Clapp C.E., Hayes M.H.B., Simpson A.J., Kingery W.L., 2005. The chemistry of soil organic matter. In Tabatabai A., and Sparks D.L. (Eds.), Chemical Processes in Soils. Soil Science Society of America, Book Series no. 8, Madison WI, $1-150$

[5] Dekker L., Doerr S., Oostinde K., Apostolos K., Ritsema, C., 2001. Water Repellency and Critical Soil Water Content in a Dune Sand. Soil Science Society of America Journal 65, 1667-1674.
[6] Doerr S.H, Shakesby R.A, Walsh R.P.D., 2000. Soil water repellency: its causes, characteristics and

hydro-geomorphological significance. Earth-Science Reviews 51, 33-65.

[7] Doerr S.H., Dekker L.W., Ritsema C.J., Shakesby R.A., Bryant R., 2002. Water repellency of soils: the influence of ambient relative humidity. Soil Science Society of America Journal 66, 401-405.

[8] Doerr S.H., Blake W.H., Shakesby, R.A., Stagnitti F., Vuurens S.H, Humphreys G.S. \& Wallbrink,P., 2004. Heating effects on water repellency in Australian eucalypt forest soils and their value in estimating wildfire soil temperatures. International Journal of Wildland Fire 13, $157-163$.

[9] Doerr S.H., Llewellyn C.T., Douglas P., Morley C.P., Mainwaring K.A., Haskins C., Johnsey L., Ritsema C.J., Stagnitty F., Allinson G., Ferreira A.J.D., Keizer J.J., Ziogas A.K, Diamantis J., 2005. Extraction of compounds associated with water repellency in sandy soils of different origin. Australian Journal of Soil Research 43, 225-237.

[10] Ghani, A., Dexter M., Perrot K.W., 2003. Hot-water extractable carbon in soils; a sensitive measurement for determining impacts of fertilisation, grazing and cultivation. Soil Biology \& Biochemistry 35, 1231-1243.

[11] Hallett, P.D., 2007. An Introduction to Soil Water Repellency. In Proceedings of the $8^{\text {th }}$ International Symposium on Adjuvants for Agrochemicals, International Society for Agrochemical Adjuvants (ISAA).

[12] Kalbitz K., Schwesig D., Schmerwitz J., Kaiser K., Haumaier L., Glaser B., Ellerbrock R., Leinweber, P., 2003. Changes in properties of soil-derived dissolved organic matter induced by biodegradation. Soil Biology \& Biochemistry 35, 1129-1142.

[13] Naafs D., Van Bergen P.F., 2002. A qualitative study on the chemical composition of ester-bound moieties in an acidic andosolic forest soil. Organic Geochemistry 33, 189-199.

[14] Nierop, K.G.J., Buurman P., 1998. Composition of soil organic matter and its water-soluble fraction under young 
vegetation on drift sand, central Netherlands. European Journal of Soil Science 49, 605-615.

[15] Nkhili E., Guyot G., Vassal N., Richard C., 2012. Extractability of water-soluble soil organic matter as monitored by spectroscopic and chromatographic analyses.
Environ Science \& Pollution Research 19, 2400-2407.

[16] Urbanek, E., Hallett, P., Feeney, D., \& Horn, R., 2007. Water repellency and distribution of hydrophilic and hydrophobic compounds in soil aggregates from different tillage systems. Geoderma, 140(1), 147-155. 